\title{
La búsqueda de Sisapo: hipótesis sobre la reducción geográfica de la capital del cinabrio hispano
}

\author{
Mar Zarzalejos Prieto *
}

\section{RESUMEN}

En este trabajo sintetizamos las diferentes propuestas de ubicación geográfica de Sisapo, la célebre ciudad del cinabrio citada por las fuentes antiguas, intentando contrastar los datos de la historiografía tradicional con la realidad arqueológica de cada sitio.

\section{SUMMARY}

In this paper the author collects diferents offerts about geographical situation of Sisapo, famous city on quicksilver production according to classical sources. Each offer has been constrasted whith the archaeological results obtained on these sites.

\section{INTRODUCCIÓN}

La búsqueda de los lugares donde situar las ciudades mencionadas por las fuentes antiguas ha constituido un ejercicio con particular desarrollo en determinadas etapas y ambientes de la historiografía arqueológica española. En no pocas ocasiones, la afortunada elección topográfica de que hicieron gala los antiguos, o la pervivencia de sus topónimos en los nombres de ciudades vivas, posibilitó la identificación inmediata de los restos de viejas urbes bajo los suelos de ciudades modernas. El caso es

* Universidad Autónoma de Madrid. 
otro cuando los núcleos no prolongaron su historia hasta nuestros días y quedaron sumidos, primero en la ruina y después en el olvido, ocultando con el paso de los siglos la memoria de su pasado y también la de su propia situación. Este hecho promovió una corriente de búsqueda, que hunde sus raíces en el Renacimiento y que hizo de la Etimología y de la Epigrafía sus bases de conocimiento fundamentales. A esta tendencia, muy ligada a los ambientes de erudición local, se sumó más tarde el interés de la investigación sobre camineria antigua. La recomposición de la traza de las viejas calzadas requería fijar el emplazamiento de las mansiones citadas por las fuentes itenerarias, con criterios muchas veces discutibles. La fortuna de estas atribuciones ha sido dispar, como desigual es también la intensidad con que la crítica contemporánea ha contrastado identificaciones, a veces muy endebles en argumentación, con el testimonio inestimable que proporciona la investigación arqueológica. Trataremos aquí el caso de una ciudad cuya reducción geográfica no ha sido posible hasta momentos muy recientes, aunque es larga la nómina de autores preocupados por su localización desde antiguo.

Sin duda alguna, evocar el nombre de Sisapo supone traer a colación el topónimo antiguo de una ciudad minera ligada de modo inequívoco a una producción singular: el cinabrio. Son diversas las menciones de que fue objeto por parte de los autores clásicos y otro género de fuentes (itinerarias, epigráficas y numismáticas) (ZARZALEJOS, 1994 b). Muchas de estas referencias enfatizan precisamente esta orientación económica por la que obtuvo fama y prestigio en la Antigüedad, a la par que constituyen un corpus informativo de partida para los diversos intentos de reducción geográfica.

El interés por identificar con un lugar concreto la ciudad de Sisapo se aglutina bajo un común denominador, que responde siempre a una búsqueda polarizada sobre el entorno más o menos inmediato de la zona dotada de la riqueza cinábrica referida por los textos: el extremo suroccidental de la provincia de Ciudad Real. Carácter también unificador posee la «antigüedad" con que fueron expuestas las reducciones, casi todas debidas a eruditos, cronistas y anticuarios desde el siglo XVI a inicios del $X I X$, y retomadas por la historiografía reciente por tradición y sin crítica correctora alguna.

Haremos a lo largo de estas páginas un repaso historiográfico sobre los puntos de mira predominantes en esta búsqueda, poniendo de relieve la información que la Arqueología ha ido añadiendo en cada caso, hasta poder ofrecer el estado de la cuestión propio de nuestros días. De entrada, conviene anotar que no es posible realizar una sistemática temporal de las tendencias, puesto que las posibilidades adaptadas al requisito minero antes citado, reducen a un estrecho cinturón geográfico las propuestas, sin que sea posible discernir periodización alguna, ni predominio de ofertas 
determinadas en épocas concretas. El único modo de dotar de cierta ordenación al discurso que sigue consiste en agrupar las opiniones de acuerdo con las propias identificaciones que se han ido sugiriendo.

\section{Sisapo $=$ Mina de Valdeazogues}

La mención más antigua sobre la ubicación del núcleo en un lugar puntual es la que ofrece el cronista Ambrosio de Morales en 1575, partidario de su relación con las labores mineras antiguas de Valdeazogues (en CORTÉS Y LÓPEZ, 1836, III, 391).

En el siglo XVIII volvemos a encontrar reflejo de esta sugerencia en el marco de la siempre emblemática España Sagrada, obra de gran envergadura dirigida por el agustino Enrique Flórez. En este meritorio trabajo, de utilidad bien demostrada como fuente moderna para algunos de los estudios propios de la disciplina arqueológica, el círculo de erudición eclesiástica se expresa de la siguiente manera:

«...Cerca de Almadén se mantienen las ruinas de Sisapon y de las minas de bermellón, en el sitio que hoy se llama Valdeazogues, a dos leguas de Almadén...» (ESPAÑA SAGRADA, 1751, VII, 140; IX, 21).

Ya en el siglo XIX, se suma a esta opinión J. De Víu, quien recoge, a modo de apéndice en su Colección de Inscripciones y Antigüedades de Extremadura, la lectura del Itinerario de Antonino que proporcionara A. de Morales (De Víu, 1846, 299). Poco antes, en 1832, las menciones de Ceán Bermúdez sobre la ubicación de Sisapo parecen inducir a cierta confusión, derivada del contenido de sus artículos sobre «Almadén» y "Valdeazogues». Dice el autor del célebre Sumario de las Antigüedades que hay en España:

«ALMADEN: ...Llamáronla los romanos Sisapon, pertenecía a la Beturia Turdula y al convento Cordubense... Famosa por sus ricas minas de azogue y conserva las ruinas de los edificios que construyeron los romanos para beneficiarlas" (CEAN, 1832, 351).

«VALDEAZOGUES: Aldea de la Provincia de la Mancha, en el Partido de Almagro, distante dos leguas de Almadén, llamado en lo antiguo como esta villa Sisapon. Ambas estaban en la región de los Turdulos beturienses y en ambas hay ruinas romanas de los edificios que tenían para beneficiar sus minas" (CEÁN, 1932, 379). La cursiva es nuestra.

De ambas referencias es posible deducir que Ceán Bermúdez no aboga por la segura identificación de Sisapo en Valdeazogues - como se ha interpretado repetidamente (SILLIĖRES, 1980, 51; CARRASCO, 1990, 87; CARRASCO, 1991, 138)-, sino en Almadén, aunque hace partícipe de la 
misma denominación a Valdeazogues, refiriéndose seguramente a la Mina y no a la aldea homónima existente entre las Sierras del Torozo y la Solana de Alcudia.

De estas propuestas de localización en Valdeazogues, cabe entresacar la íntima relación que, desde antiguo, se establece entre el lugar de Sisapo y las propias minas, en cuyo entorno se conservó indicio de frecuentación romana. Las noticias transmitidas por Flórez sobre Valdeazogues, como las proporcionadas antes por Morales, se refieren a la existencia de ruinas "en el sitio que hoy se llama Valdeazogue a dos leguas de Almadén» (ESPAÑA SAGRADA, 1751, VII, 140). Será precisamente esta indicación de distancia la que permita efectuar la distinción entre «Mina Valdeazogues" (Almadenejos) y la aldea de Valdeazogues perteneciente al término municipal de Almodóvar del Campo y bastante más alejada de Almadén de lo que indican Morales y Flórez. En los Diccionarios del siglo pasado se refiere a Valdeazogues como "aldea», sin mención expresa a la presencia de vestigios antiguos y aludiendo con seguridad al pequeño pueblo situado entre las Sierras del Torozo y la Solana de Alcudia (MiÑANo, 1826, IX, 163; MAdoz, 1846$50, X V, 367)$.

Ceán, como se ha indicado líneas arriba, apunta la persistencia en el lugar de "ruinas romanas de los edificios que tenían para beneficiar sus minas» (CEÁN, 1832, 379). También Coello alude a los indicios de intervención romana en las «minetas de Valdeazogues» (COELLO, 1889, 21). En este sentido, hemos de anotar que efectivamente ha sido reconocida la existencia de trabajos antiguos en la mina de cinabrio de «El Entredicho" (ZARRALUQUI, 1934, 124), junto a restos arruinados de explotaciones modernas, así como en el exterior del cerco de fundición moderno de "Las Minetas», al otro lado del río Valdeazogues (DOMERGUE, 1987, 64-65, núm. 6). Es posible que los trabajos del siglo XIX, en los que se documentaron algunos objetos romanos (DOMERGUE, 1987, 65), borraran toda huella de edificaciones anteriores, puesto que, en 1900, Pontes advierte que «sus alredores no contienen señal alguna de la opulencia de Sisapo, ni en ellos se ve restos de población antigua" (PONTES, 1900, 81). No obstante, la entidad de las ruinas, de las que hoy en día sólo subsisten las pertenecientes a instalaciones modernas, no debió ser superior a las que correspondían a un poblado minero cuya importancia aún no ha sido confirmada por vía arqueológica.

Sisapo $=$ Chillón

Esta hipótesis no cuenta, en verdad, con alto número de seguidores, si 
bien, la afiliación a ella de algunos de los más notorios historiadores de la provincia de Ciudad Real justifica que se enuncie en este seguimiento.

La referencia más antigua a la identificación de Sisapo en Chillón nos viene dada por un manuscrito del siglo XVIII, obra de un Carmelita Descalzo vecino de esta localidad. El documento fue dado a conocer a través de una copia con caligrafía del siglo XIX, por D. Ildefonso Romero García, canónigo penitenciario de la Santa Iglesia Prioral de Ciudad Real (ROMERO, 1954). La fecha en que calcula este autor que pudo ser escrita la Historia de Chillón de Fr. Cayetano del Santísimo, nombre religioso del Carmelita, es de 1783-4 (ROMERo, 1954, 8).

De Chillón dirá este historiador local:

«...Sentado este punto cierto e indubitable, según nuestra topografía, se infiere claramente que aqui y no en otra parte se debe colocar y poner el Sisapón, que dió nombre a la región... Venerando, pues, todos los parecereces y dictámenes, decimos que el Sisapón, capital de la Región Sisaponense miniaria o cinabria, es la villa de Chillón. Las minas de cinabrio de la región Sisaponense cinabrina han sido conocidas desde 1168 por el territorio baldío de Chillón. No hubo jamás otra región Sisaponense, que haya dado cinabrio, luego la capital es Chillón» (ROMERo, 1954, 22).

Según puede deducirse del texto, escrito siempre dentro de este tono de exaltado amor local, los argumentos que emplea el religioso para descartar Almadén como solar de Sisapo emanan de varios documentos de donación de los siglos XI y XIII en los que Almadén aparece mencionado con el significado estricto de «mina» de Chillón, de donde deduce que no existía aún población permanente en Almadén.

Ya a principios de nuestro siglo, el epigrafista Fidel Fita vuelve a conceder atención a las posibilidades de asociar Sisapo con Chillón. En su estudio sobre una inscripción funeraria descubierta en las proximidades de Almadén afirmará lo siguiente:

«... A esta villa de la provincia de Ciudad Real [Almadén], famosa por sus minas de azogue, se reduce la ciudad que Cicerón, Estrabón, Plinio y Ptolomeo denominaron Sisapo. Todos los códices del Itinerario de Antonino, sin excepción, la llaman Sisalone y hasta hoy se ha creído que está mal escrito en vez de Sisapone, mas no se repara en que, tres kilómetros al E. de Almadén se encuentra la villa de Chillón con su nombre directamente formado de Sis(a)lon(e)" (FITA, 1910, 527).

Con argumentos en consonancia con la supuesta modernidad del establecimiento de población en Almadén, vuelve a defender esta ubicación D. Inocencio Hervás Buendía. A estas razones añade otros considerandos 
que tienen que ver con las características topográficas del Cerro de Nuestra Señora del Castillo, lugar puntual de la geografía de Chillón donde considera que se emplazó Sisapo:

«...tenemos por cierto que fue el asiento de Sisapón la ladera del Cerro de Nuestra Señora del Castillo. A esta creencia nos impulsa, el que la Población de Almadén nació a consecuencia del descubrimiento de su Mina... La identidad de la situación de Sisapo con la de Oreto y demás ciudades antiguas no puede ser mayor. Recostábanse de ordinario sobre el monte a que daban nombre, coronado por fuerte castillo..." (HERVÁs, 1914, 425).

Opinión semejante aducen D. Manuel Corchado Soriano (CORCHADO, 1969, 156; CORCHADO, 1982, 43) y D. Julio Zarraluqui Martínez, para quien la confluencia en Chillón de tres caminos antiguos es un factor más de confirmación, adicionable a los tan manejados documentos en los que Almadén se cita como la mina enclavada en territorio de Chillón (ZarRaluQui, 1934, 104 y 107).

La postura defendida por estos autores, reincide nuevamente en la asociación Sisapo=minas de cinabrio, combatiendo esta vez, con los argumentos que asocian la pertenencia histórica de las minas a Chillón. Al margen de estas consideraciones, Coello se refiere a la existencia en Chillón de "ruinas antiguas y de los árabes" (COELLO, 1889, 21), como también Corchado alude a la detección de urestos romanos y anterromanos en el pueblo» (CORCHADO, 1969, 151). Algo más extraño resulta el reconocimiento por parte de Hervás, igualmente partidario de ubicar Sisapo en Chillón, de la inexistencia de vestigios antiguos: "No importa el que no se hallen hoy en aquellos labrados restos de construcciones ni materiales extraños a aquel suelo» (HERVÁs, 1914, 425); mientras, algunas páginas adelante menciona la existencia de «ruinas de edificación antigua» en los alrededores del Convento de San Antonio (HeRVÁs, 1914, 430).

Evidencias de labores romanas constan en la fundición de San Pablo, a $6 \mathrm{~km}$. al SW. de Chillón; los materiales dispersos en superficie acreditan que el establecimiento se mantuvo activo entre el siglo II-I a.C. y el I. d.C. (Campaniense B, lucernas mineras, T.S.I., T.S.G., ánforas Dr. 1, etc. (DOMERGue, 1987, 75, núm. 31). Igualmente de Chillón proceden una estela del SW reutilizada en época romana (FERNÁNDEZ OCHOA y ZARZALEJOS, 1993 b) y otras dos lápidas funerarias romanas depositadas en el Museo Provincial de Ciudad Real.

Desde nuestro punto de vista, no constituye esta serie de hallazgos un testimonio definitivo que permita poner fin al litigio de la reducción geográfica de la ciudad tal y como ya apuntara el propio Hervás (HERVÁs, 1914,430 ). En todo caso, hacemos constar que los restos conocidos 
hasta el momento, carecen de la relevancia y el interés que cabría atribuir a la cabeza de un distrito minero, pudiendo ser considerados, a lo sumo, indicios de población romana a pie de mina.

\section{Sisapo $=$ Almadén}

Llegamos finalmente a la proposición que ha gozado de mayor número de seguidores hasta nuestros días. Entre la larguísima nómina de autores que se adhieren a esta propuesta de reducción cabría distinguir el empleo de dos líneas argumentales no excluyentes entre sí. Por un lado, se hallarian los razonamientos que pudiéramos denominar de índole «minera» y por otro, los que apoyan en razones «viarias». A ellos se añade, finalmente, un grupo nutrido de investigadores contemporáneos que asumen la propuesta de manera mecánica y sin argumentación de ningún tipo.

Entre los primeros, habría que incluir las opiniones de historiadores y autores de obras de carácter enciclopédico. Una referencia elocuente, y también algo despistada por la atribución del nombre antiguo en Ptolomeo (II, 5), será la de Miñano en su Diccionario geográfico-estadístico de España y Portugal:

«Almadén...Sisapona cetobrix... Situada sobre una colina de cinabrio entre dos cumbres que son ramales de Sierra Morena... Es constante que labraron esta mina los romanos, pero después acá es tanto lo que en ella se ha revuelto que no quedan indicios de sus trabajo..." (MIÑANO, 1826, I, 151).

También en este marco, y como ya hemos tenido oportunidad de comprobar antes, se inscribirán los comentarios de Cortés y López sobre una Sisapo Beturiae Celtica y la Sisapo Regionis Osintiadae, que considera asimilables a Almadén de la Plata (Sevilla) y Almadén del Azogue (Ciudad Real), respectivamente (CORTÉs y LóPEZ, 1836, III, 390-1), en idéntica línea a la que desarrolla a principios de siglo J.M. Pontes y Fernández (PONTES, 1900, 75-76).

Fuente semejante vuelve a manejar J. de Hosta en su Crónica de la Provincia de Ciudad Real, que se refiere en Almadén diciendo que fue villa antiquísima, cuya fundación se atribuye a los celtas; que la llamaron Sisapo, en cuya lengua significa "mina» (HostA, 1865, 85).

El segundo grupo de defensores de la reducción Sisapo =. Almadén está compuesto en gran medida por autores interesados en las cuestiones camineras. Todos ellos parten de un principio común: la equivalencia entre 
la Sisalone mencionada por el Itinerario de Antonino en la vía Per Lusitaniam ab Emerita Caesarea Augusta con la Sisapo citada por fuentes literarias geográficas y epigráficas ${ }^{1}$. Los intentos de reducir sobre el mapa el trazado de esta ruta cristalizaron en propuestas de ubicación para las mansiones referidas por el documento itinerario (ZARZALEJOS, 1994 a, 160 ss.). En el caso particular que nos ocupa, se argumenta esta identificación a partir de la coincidencia de la distancia miliaria antoniniana entre Almadén y Capilla, que se suponía sede de Mirobriga ${ }^{2}$. La propuesta estaba refrendada, a su vez, por la riqueza en cinabrio que sin duda posee Almadén. Los más conocidos defensores de esta hipótesis han sido $\mathrm{E}$. Saavedra, Coello, Miller (SaAvedra, 1862, 103; Coello, 1889, 20; Miller, 1916, 159), y, sobre todo, A. Blázquez (BlázQuez, 1892, 280; BlázQuez, 1912, 368; BlÁzQuez-SÁnchez Albornoz, 1917, 23).

Con independencia de la operatividad de estas proposiciones viarias y sin entrar más de lleno en un problema ajeno a la cuestión que ahora se trata, deseamos hacer notar que Almadén se ha consagrado en la bibliografía arqueológica como asiento indiscutible de Sisapo. Buena parte de las referencias parecen mecánicas y no ofrecen planteamientos propios en los que se cuestione críticamente la realidad de esta ubicación, (GONZÁLEZ ROMÁN, 1981, 141; Alvarez et ALII, 1985, 133; Fernández CoRRAles, 1987, 62-63; Pastor-Pachón, 1991 b, 347; Corzo-Toscano, 1992, 183 y 185; Pastor et ALII, 1992, 16 y 24; PASTOR-PACHÓN, 1993, 46).

Por lo que respecta a la ecuación Sisapo = Almadén, debe anotarse de entrada, como ya advirtiera Silliéres y antes que él otros autores (GARCíA DE LA SANTA, 1955, 677; SAUPe, 19-73, 227-237; Sillieres, 1980, 50), que los yacimientos de cinabrio no son privativos de Almadén, puesto que las minas se extienden en terrenos de Chillón y Almadenejos. Esta realidad anula el planteamiento que asocia con carácter exclusivo Sisapo con Almadén en virtud de la riqueza en bermellón de su subsuelo, tan elogiada por los autores clásicos. Repasemos pues, las evidencias arqueológicas de que dispone hasta el presente la ciudad y veamos la entidad y naturaleza de sus restos del pasado.

La equivalencia Sisalone = Sisapone parece no generar demasiadas discrepancias en bibliografía más reciente (Roldán, 1975, 93; Sillieres, 1980, 52; FeRnández CoRfales, 1987, 60; CARRASCO, 1990, 87; SllLieRES, 1990, 22, not. 10). El único autor que plantea dudas sobre esta posible solución es $\mathrm{G}$. Arias, que considera que pudiera tratarse de dos mansiones diferentes (ARIAS, 1990, 6).

2 Problema de distinta índole planteaba la medición de millas entre Almadén y Caracuel, almenos si se admitía la relación de ésta con la Carcuvium antoniniana, según hemos tratado con profundidad en otro trabajo (ZARZALEJos, 1994 a, 225 ss.). 
Buena parte de los autores del siglo XIX que defienden la identificación que ahora tratamos, se limitan a ofrecer datos sobre explotaciones mineras antiguas, sin describir ruinas $u$ otros restos asociables a la ciudad romana (MIÑANO, 1826, I, 151-152; CORTÉs, 1836, III, 391); en otros casos, a este argumento se suma el de la coincidencia de la distancia del Itinerario hasta Mirobriga como resultado de los cálculos efectuados con el valor de la milla propuesto en cada momento (13 m.p. = $22 \mathrm{~km}$.) (BLÁZQUEZ, 1898, 67; BLÁZQUEZ, 1912, 368).

Ceán indica la conservación en Almadén de «ruinas de los edificios que construyeron los romanos para beneficiarlas (las minas)" (CEÁN, 1832, 351). En la misma línea se inscribirían las noticias de Coello cuando refiere la opinión de algunos autores según los cuales Sisapo se hallaría «en el paraje de Las Cuevas, al NE de la villa actual, donde hay vestigios de población y están los de las minas más antiguas, es posible que allí hubiese también algún barrio importante» (COELLO, 1889, 20).

Algo más explícito en cuanto a la naturaleza de los restos será Pontes:

\begin{abstract}
"Hacía el E. de Almadén aún se notan cimientos de fuertes obras en sitios incultos hoy u ocupados por los cercados... Informes adquiridos de personas muy conocedoras de Almadén, confirman las anteriores noticias y añaden que labrando en los alredores de la villa, la reja del arado encontró fuerte resistencia descubriéndose al fin una sepultura compuesta de grandes piedras y cubierta con otra» (PONTES, 1900, 80).
\end{abstract}

Prescindiendo de los argumentos, no carentes de cierto antagonismo local, que hacen de Almadén originariamente la mina de Chillón (HERVÁs, 1914, 85; CORCHADO, 1982, 43), lo cierto es que se conocen labores mineras antiguas en diversos puntos del territorio incluído en el término municipal de Almadén. Destaca por su importancia la mina de Las Cuevas, ya citada por Coello, donde los trabajos alcanzaron los $100 \mathrm{~m}$. de profundidad y donde aún hoy resultan visibles restos cerámicos romanos en superficie (T.S.H. y cerámica común) y monedas, correspondientes sin duda a un asentamiento relacionado con la explotación en el llamado significativamente "Cerro de los Ladrillos» (DOMERGUe, 1987, 63, núm. 4). También en la zona de «Quinto del Hierro" se han detectado diversos habitats romanos siempre en relación a yacimientos mineros o fundiciones, con materiales de superficie cuya cronología se remonta a los siglos II-I a.C. (DOMERGUE, 1987, 63-64, núm. 5). Asimismo poseemos datos facilitados por el Grupo de Estudios de Almadén y Comarca dependiente de la Universidad Popular de esta localidad, que ratifican las noticias anteriores; según comunicación de este grupo, en 1984 tuvo lugar la localización de una necrópolis al E. de la llamada «Fuente del Hierro", de donde procede la lápida funeraria de Torius Bilosfe que se halla expuesta en la Casa de Cultura de Almadén. 
A estas evidencias debe sumarse el hallazgo a principios de siglo de otro epígrafe procedente del N. de Almadén publicado por Fita (FITA, 1910, 527528).

Considerando la naturaleza y extensión de los restos descubiertos hasta el momento, se advierte que parecen estar relacionados en gran medida, con las explotaciones romanas de minio y plata sobre cuyas reservas no es necesario insistir (LAURET-TAMAIN, 1975, 61-69); por esta razón pudiera tratarse de asentamientos mineros y sus correspondientes áreas de necrópolis, desprovistos, por ende, de la importancia que debió tener la Sisapo citada por las fuentes.

Con independencia de que subsistan en Almadén vestigios de época romana, pensamos, como en el caso de Valdeazogues y Chillón, que no existen indicios que permitan defender la existencia en este lugar de un yacimiento que pueda ser identificado con Sisapo. Efectivamente, algunas de las minas de cinabrio con labores antiguas están en el entorno de Almadén, pero ello no significa que la ciudad que las gestionó hubiera de ubicarse necesariamente junto a ellas. Al margen de los problemas de incomodidad e insalubridad que derivarían de este emplazamiento, Almadén no reúne, según los datos conocidos hasta hoy, las condiciones de estrategia de control geopolítico, económico y caminero que debió poseer el centro gestor de las explotaciones.

\section{Sisapo $=$ Cerro de Las Monas}

Debemos mencionar, aunque con suma brevedad, la hipótesis enunciada por Sillières hace ya algunos años y que trataba de ofrecer nuevas posibilidades de acercamiento al espinoso problema de la vía 29 del Itinerario de Antonino (SILLIÈRES, 1980). La traemos aquí - con independencia de que el autor haya matizado a posteriori su opinión-como un argumento más sobre la inoperancia arqueológica de las reducciones que hemos ido mencionando en las páginas anteriores. La emisión de esta nueva sugerencia partió de la aplicación del método prospectivo y como contrapartida a las débiles argumentaciones arqueológicas que pudieran explicar la localización de la ciudad en los puntos antes citados.

La búsqueda mediante prospección de un gran yacimiento antiguo que pudiera ser solar de la mansio Sisapo, obtuvo como resultado el reconocimiento del Cerro de las Monas entre los ríos Valdeazogues y Alcudia. El lugar, cuyos restos parecen acreditar una ocupación espacial cercana a las 6 Ha., cuenta con doble facies - prerromana y romana-y parece responder más a un modelo de emplazamiento funcional en un punto de confluencia 
que a los oppida tan frecuentes en la región (SILLIĖRES, 1980, 53). Pese al evidente interés que este yacimiento ofrece, lo cierto es que tras los descubrimientos realizados en La Bienvenida, el autor galo considera la posibilidad de que pudiera ser este último lugar la sede de la ciudad, y el Cerro de las Monas quizá una mansio omitida en el documento antoniniano (SILLIĖRES, 1990,375 y 382).

\section{Sisapo = La Bienvenida}

La alusión más antigua sobre la existencia de ruinas antiguas en La Bienvenida consta en las Relaciones Topográficas de Felipe II, donde en la respuesta 51 de las Relaciones de Almodóvar se indica:

«... La Bienvenida está en la dehesa de Alcudia... es sitio a do se han hallado muchas monedas antiguas de romanos, y otros edificios y lugares antiguos... 》 (VIÑAS-PAZ, 1971, 63 ss.).

La primera propuesta de ubicación de Sisapo en La Bienvenida fue emitida por D. Angel Delgado, erudito y conocido anticuario natural de Belalcázar (Córdoba), en el vecino valle de los Pedroches; de ella encontramos razón en los trabajos firmados por otros autores, como el propio A. Blázquez, I. Hervás o Fr. J. Ruiz (BlÁzQUEz, 1912, 365; HeRvás, 1914, 164-165; RuIz, 1923, 78):

«Siempre en las varias veces que visité la Bienvenida de Alcudia, su situación en punto céntrico, sus ruinas, los vestigios de los caminos que la unían ya con Almadén, o sea las minas de Bermellón, que explotaba Roma, ya con Castulón, ya con la Virgen de las Cruces por el Puerto del Mochuelo, ya con la Oretania por el puerto de Veredas, me han hecho pensar, que pudiera ser muy bien Sisapón, la Bienvenida, y si tal cosa se probara, estaba ya explicada la lápida número 3.270 de Hübner, que coincide con los restos de caminos de que hablan el Sr. Blázquez y otros sabios arqueólogos, y este descubrimiento comprobado vendría a fijar indubitablemente el verdadero Salto Constulonense, por donde según dicha lápida iba el carnino de Castulón a Sisapón» (en HeRvÁs, 1914, 165).

Aunque no se decantan los citados autores por confirmar la impresión de Delgado, todos ellos corroboran la existencia de ruinas de importancia en La Bienvenida. Así Blázquez dirá en uno de sus trabajos:

«...Son numerosos los vestigios más o menos importantes que se observan en Bienvenida, en donde mi difunto hermano D. Manuel opina que hubo circo... hay extensos escoriales romanos al $\mathrm{N}$. de Bienvenida, en la inmediación del camino antiguo que viene de Almadén y continúa a la Veredilla». (BLÁZQUEZ, 1898, 45 y not. 1). 
El comentario que este autor incluye en otra de sus obras posibilita comprobar de mejor manera lo inductivo de la búsqueda de Sisapo en el entorno de Almadén, y las razones para rechazar su ubicación en La Bienvenida con un argumento al que ya hemos hecho mención al referir la riqueza minera del entorno inmediato al yacimiento:

«... respecto a las ruinas de Bienvenida y a las minas inmediatas, deberá recordarse que si Sisapone le caracterizaban las minas de cinabrio y las inmediatas a Bienvenida, explotada alguna de ella en la época romana, son de galena, y hubiera sido cosa incomprensible que, tratándose de una explotación importante de estos minerales, de los cuales quedan escorias abundantes, hubiera dicho que en Bienvenida se obtenía el azogue en vez del plomo argentífero o galena» (BLÁZQUEZ, 1912, 366-7).

Bastantes años después, en 1953, la prensa provincial de Ciudad Real se hace eco de un aviso realizado por el presbítero D. Edistio-Silvestre Sancho acerca de la existencia de estos vestigios importantes en La Bienvenida. La noticia fue recogida en el Inventario Nacional de Folios Arqueológicos del N.A.H.:

«Almodóvar del Campo (Ciudad Real).- El cura Párroco, don EdistioSilvestre Sancho, informa acerca de la localización de una ciudad romana junto a la iglesia de Nuestra Señora de las Candelas, filial de la Parroquial. Se encontraron sarcófagos con restos humanos, monedas, ladrillos, etc. A pocos metros parece encontrarse un teatro cubierto de tierra. En la parte sur de la aldea se han encontrado mosaicos y restos de columnas". (INVENTARIO FOLIOS ARQUEOLÓGICOS, 1953, 207, $n^{\circ}$ 649).

Dos años después, y con motivo de una primera intervención en el yacimiento, D. Tomás García de la Santa publica unas notas en las que se describen someramente algunos de los hallazgos y se propone la verosimilitud de la ubicación de Sisapo en La Bienvenida (GARCíA DE LA SANTA, 1955, 673 ss.). En esta ocasión, se menciona la localización de los restọ sobre los que se centró la actuación auspiciada por el Ayto. de Almodóvar:

«...Como resultado de nuestra visita indicamos la conveniencia de excavar en la explanada casi rectangular, que asciende suavemente desde el «Hoyo santo" hasta el «castillejo", y, efectivamente, se encontró alli con facilidad un peristilo casi completo con pavimento de mármol, las bases de todas las columnas y porciones de éstas y de los capiteles" (GARCIA DE LA SANTA, 1955, 675-6).

Una descripción similar, o quizá algo más completa, de la entidad de los vestigios reconocidos - especialmente los de carácter funerario-, aparece en una publicación posterior de Sancho y García de la Santa (SANCHO-GARCIA DE LA SANTA, 1960, 27 ss.). En ella se da cuenta de la existencia de abundantes sepulcros pétreos en el camino que parte hacia Almadén: 


\begin{abstract}
«Los restos de estas cámaras sepulcrales que hemos examinado presentan características muy semejantes. Se trata de cajas de piedra rectangulares al exterior $(0,59 \times i 1,607 ? \times 0,40)$ y ligeramente trapeciales en su vaciado que mide aproximadamente $0,43 \mathrm{~m}$. de ancho en el lugar de la cabeza $\times 0,37$ en el extremo opuesto $\times 0,25$ de fondo. La piedra a primera vista parece artificial (opus caementicium) pero hemos comprobado la existencia en lugar próximo de rocas de la misma composición. Se trata de una toba que se presenta en distintos grados de dureza y, con frecuencia, muy disgregada. Sobre el cadáver se encuentra una capa de tierra fina y cernida... y a la izquierda de la cabeza, junto a la boca, hay una vasija. De éstas, la única que hemos visto y otras que tenemos referencias son de barro grosero, con pequeñísimos puntos al parecer de cobre... Su fondo y al lado opuesto al asa parecen haber estado sometidos a la acción del fuego, como si se tratara de una vasija casera muy usada..." (SANCHO-GARCIA DE LA SANTA, 1960, 34-5).
\end{abstract}

Salvo estas escuetas noticias, nada más ha podido saberse de las actuaciones en el yacimiento durante aquellos años, dado que la Institución que las promovió no conserva documentación escrita o material que pudiera servirnos de mayor ayuda.

Los siguientes treinta años de historia del yacimiento mantienen en silencio ataques contínuos a su integridad y la desaparición de algunos de sus tan celebrados restos (columnas, capiteles), visibles todavía hoy en la puerta de alguna finca cercana, según hemos comprobado durante nuestras prospecciones. En 1980 se abre la fase de investigación y excavación sistemática del lugar, en la que se han practicado intervenciones constreñidas siempre al espacio protegido por una estructura defensiva bien perceptible por fotografía aérea y confirmada por vía arqueológica ${ }^{3}$. El hallazgo en 1982 de un epígrafe con parte del nombre de Sisapo (FERNÁNDEZ OCHOA ET ALII, 1982-83), constituyó un indicio bastante valorado en los ambientes epigráficos e históricos para poder mantener con verosimilitud el binomio Sisapo = La Bienvenida. En este sentido se han expresado algunos especialistas en los últimos años (STYLOW, 1985, 658; ALFÖLDY, 1987, 54-8).

No volveremos a reiterar aquí las consideraciones concernientes al análisis del epígrafe, cuyo estudio está contenido en publicaciones ya citadas (FERNÁNDEZ OCHOA ET ALII, 1982-83; ALFÖLDY, 1987, 54-8) y al que se dedica lugar propio en otro trabajo (ZARZALEJOS, 1994 b). Sin embargo,

3 Sucesivas campañas hasta el año en curso certifican la importancia del enclave y su riqueza material, reflejada ya en numerosas publicaciones (AURRECOEHEA ET ALII, 1986; Fernández Ochoa-Seldas, 1987; Zarzalejos-García, 1987; Zarzalejos-Seldas, 1987; Fernández Ochoa-Caballero, 1988; Fernández Ochoa et alil, 1994; Fernández Ochoa-Zarzalejos, 1991; Fernández Ochoa-Zarzalejos, 1992 a y b; Fernández Ochoa-Zarzalejos, 1993 a; Zarzalejos et ALII, 1993). 
opinamos que tan interesante hallazgo no es el único elemento de juicio en que reposa la identificación, dado que no faltaría quien pudiera considerarlo con cautela a causa de su conservación fragmentaria. La verosimilitud de esta propuesta de ubicación complementa este documento epigráfico con resultados arqueológicos innegablemente reveladores. La información derivada de los sondeos estratigráficos practicados, pone de relieve una ocupación del lugar remontable a fines del siglo VIII a.C. y continuada, salvo algunos hiatos, hasta el siglo IV d.C. (ZARZALEJOS, 1994 a; FernándeZ OCHOA ET ALII, 1994). Al interés intrínseco que proporciona la identificación de niveles habitacionales tan antiguos, se añade el testimonio interesante del hallazgo de fragmentos de cuarcita con impregnación en cinabrio en el estrato de base del sondeo A-1 (a b) (fines siglo VIII-principios VII a.C.). Tal indicio podría estar apuntando pistas a la hora de entrever viejas relaciones de este sitio con el cinabrio, de cuyas fuentes naturales dista casi $40 \mathrm{~km}$. En suma, podría sintetizarse que, a través de la interpretación de los resultados arqueológicos obtenidos en estos años de intervención sistemática y mientras no surjan nuevos descubrimientos en esta zona que invaliden la hipótesis, estamos en condiciones de mantener la propuesta que hace de La Bienvenida el asiento de la ciudad de Sisapo.

A los argumentos que rápidamente hemos ido enumerando se adicionarían, además, todos los factores de estrategia que convergen en este punto de Alcudia y a los que se ha dedicado especial atención en otros lugares (ZARZALEJOS, 1994 a). En síntesis, La Bienvenida ofrece una inmejorable situación topográfica puesto que ocupa una meseta situada a $620 \mathrm{~m}$. de altitud y en vecindad muy próxima a las cotas más elevadas de este sector centro occidental del Valle de Alcudia (los Castillejos de La Bienvenida), con cimas que superan los $700 \mathrm{~m}$. de altura y permiten una excelente visualización del entorno en los cuatro puntos cardinales. El factor estratégico de visibilidad encuentra en este lugar condiciones óptimas para el emplazamiento de una ciudad que precisa de estos atributos de control espacial. A la hora de establecer hipótesis de estrategia económica que pudieran explicar la elección del sitio, hemos barajado la oferta del medio en recursos potencialmente explotables. Fruto de un análisis bastante detallado, podría defenderse que pudo ser el recurso minero el factor que condicionó la ubicación de Sisapo en el lugar de La Bienvenida, puesto que el enclave se encuentra situado en posición ventajosa para el control y la explotación de una doble reserva en recursos minerales: el cinabrio y la galena argentífera (ZARZALEJOS, 1994 a) ${ }^{4}$.

\footnotetext{
4 La relación entre Sisapo y la explotación de la plata está contenida en una referencia de Estrabón (III, 2, 3). No obstante, el tradicional vínculo entre la ciudad y el cinabrio ha hecho pasar desapercibida esta afirmación. Así A. Blázquez rechaza la identificación de Sisapo en La
} 
Si éstos son los argumentos proclives a mantener la propuesta de ubicación que defendemos, no es menos cierto que permanece sin solución un problema, cual es la falta de coincidencia en las distancias recogidas por el Itinerario de Antonino entre las mansiones de Mirobriga, Sisapo y Carcuvium y la que media realmente entre el Cerro del Cabezo (Capilla, Badajoz), La Bienvenida y Caracuel. Un estudioso de este camino, P. Silliéres, ha proporcionado posibles soluciones a estas discordancias, que se saldan con la incorporación a la vía de una mansio omitida (El Cerro de las Monas) y la corrección en el número de millas que separaron Sisapo de Carcuvium (SILLIĖRES, 1990, 378). Por nuestra parte, debemos reiterar la cautela con que debe aceptarse toda propuesta de solución que tenga que ver con rectificaciones al documento antoniniano, puesto que no pasan de ser hipótesis para las que en el presente no puede haber confirmación (ZARZALEJOS, 1994 a).

Así las cosas, la exposición que antecede a estas líneas finales contiene la síntesis derivable del estado de conocimientos vigente hasta nuestros días. Es posible que futuros análisis en el yacimiento de La Bienvenida, o de modo más amplio en el extremo Suroccidental de Ciudad Real, puedan proporcionar una visión que complemente a la que ahora ofrecemos o que, por el contrario, la matice o modifique substancialmente. El problema queda abierto y sometido a debate en cuanto sea posible adicionar información nueva y diferente a la que hasta hoy se maneja.

\section{BIBLIOGRAFIA CITADA EN EL TEXTO}

ALFölDY, G., 1987: Römisches Städfewosen auf der Neukastilischen Hochebene, Heidelberg.

ALvAREZ, J.M. ET ALll, 1985: «El tiempo antiguo», Historia de Extremadura, Vol. I, Badajoz.

ARIAS, G., 1990: «Laminio, Sisapo y Titulcia en Alföldy", El Miliario Extravagante, 25, La Línea, Cádiz.

ARRECOECHEA, J. ET ALII, 1986: «Mobiliario metálico romano del yacimiento romano de La Bienvenida, Ciudad Real», Oretum, II, Ciudad Real.

BLAZQUeZ, A., 1892: "Vías romanas de la provincia de Ciudad Real», B.R.S.G., XXXII, Madrid.

BLAZZUEZ, A., 1898: Historia de la provincia de Ciudad Real, Avila.

BLAZQUEZ, A., 1912: "Vías romanas de la Beturia de los Turdulos», B.R.A.H., 61, Madrid.

BLÁZQUez, A., y SÁNCHEZ AlboRnoz, C., 1917: Vías romanas del Valle del Duero y Castilla La Nueva, M.J.S.E.A., 2, Madrid.

CARRAsco, G., 1990: «Introducción al estudio de las vías romanas de la provincia de Ciudad Real», Simposio La red viaria en la Hispania Romana, Tarazona 1987, Zaragoza 1990.

CARRASCO, G., 1991: "La Oretania romana: aportación a su conocimento», Cuad. Est. Manch., 20, Ciudad Real.

CEÁN BERMúdEZ, M., 1832: Sumario de las antigüedades romanas que hay en España", Madrid.

Bienvenida por estar ésta en zona productora de plata y no de cinabrio (BLÁZQUEZ, 1912, 366-7). Más recientemente se ha interpretado esta alusión a la plata de la comarca sisaponense como un error de Estrabón al tomar la referencia de Asclepiades de Mirlea (Prieto, 1973, 135). 
CoelLo, F., 1889: «Vías romanas entre Toledo y Mérida», B.R.A.H., XV, pp. 5-42, Madrid.

CORCHADO, M., 1969: «Estudios sobre vías romanas entre el Tajo y el Guadalquivir», Arch. Esp. Ars. Arq., 42, Madrid.

CoRCHAdo, M., 1982: El Campo de Calatrava. Los Pueblos. Ciudad Real.

CORTES Y LóPEZ, M., 1836: Diccionario geográfico-histórico de la España Antigua. Tarraconense, Bética y Lusitania, 3, vol., Madrid.

Corzo, R. y TOSCANo, M., 1992: Las vías romanas de Andalucía, Sevilla.

Domergue, C., 1987: Catalogue des mines et des fonderies antiques de la Péninsule lbérique, Madrid.

España SAGRADA, 1751: Flórez, E. (dir.): España Sagrada. Teatro geográfico-histórico de la lglesia en España, Vol. VIII.

FERNANDEZ CORRALES, J.M., 1987: El trazado de las vías romanas en Extremadura, Madrid.

FERNANDEZ OCHOA, C. ET ALII, 1982-3: "Nuevo documento epigráfico para la localización de Sisapo", CUPAUAM, 9-10, Madrid.

FERnÁNDEZ OCHOA, C. ET Alll, 1994: Sisapo I. Excavaciones en el yacimiento de La Bienvenida (Almodóvar del Campo, Ciudad Real), (e.p.).

FERNÁNDEZ OCHOA, C. y CABALLERO, A., 1988: «El horizonte histórico de La Bienvenida y su posible identificación con la antigua Sisapos, I Congreso de Historia de Castilla-La Mancha, Ciudad Real, 1985.

FERNÁNDEZ OCHOA, C. y ZARZALEJOS, M., 1991: «Las producciones de Terra Sigillata Altoimperial de Sisapo (La Bienvenida, Ciudad Real) l», Espacio, Tiempo y Forma, Serie Il, 4, Madrid.

Fernández OCHOA, C. y ZARZAlEjos,M., 1992 a: «Excavaciones en la antigua Sisapo», Rev. de Arqueologia, 132, Madrid.

Fernández OchoA, C. y Zarzalejos,M., 1992 b: "Terra Sigillata Hispánica Brillante de Sisapo (La Bienvenida, Ciudad Real)», Bol. Asoc. Am. Arq., 32, Madrid.

FernándeZ OCHOA, C. y ZARZALEJOS,M., 1993 a: «Las producciones de Terra Sigillata Altoimperial de Sisapo (La Bienvenida, Ciudad Real) II", Espacio, Tiempo y forma, Serie II, 6, Madrid.

Fernández OCHOA, C. y Zarzalejos,M., 1993 a: "La estela de Chillón (Ciudad Real). Algunas consideraciones acerca de la funcionalidad de las "estelas de guerrero" del Bronce Final», V Congreso Internacional de Estelas Funerarias, Soria (e.p.).

FITA, F., 1910: «Lápida romana de Almadén», B.R.A.H., 56, Madrid.

GARCIA DE LA SANTA, T., 1955: “¿Saesapo?. Un poblado romano en el Valle de Alcudia (Almodóvar del Campo, Ciudad Real)", Rev. Arch. Bib. Mus., 61, Madrid.

GonzAlez RomÁ, C., 1981: Imperialismo y Romanización en la Provincia Hispania Ulterior, Granada.

HeRVÁs, 1., 1914: Diccionario histórico geográfico, biográfico y bibliográfico de la Provincia de Ciudad Real, Ciudad Real, $1^{2}$ ed. 1890.

HOSTA, J. DE, 1865: Crónica de la provincia de Ciudad Real, Madrid.

LAURET, J.M. y TAMAIN, G., 1975: “L' antique mine d'argent de Quinto del Hierro à Almadenejos (Ciudad Real, Espagne)", 98 Congrés National des Societés Savantes, Saint Etienne 1973, París.

MADOZ, 1846-50: Madoz, P.: Diccionario geográfico-estdístico-histórico de España y sus posesiones de ultramar, 16 vol. Madrid.

MILLER, K., 1916: Itineraria Romana. Römische Reisewege an der Hand der Tabula Peutingeriana, Stuttgart.

Minano, S., 1826: Diccionario geográfico-estadístico de España y Portugal, Madrid.

PASTOR, M. y PACHÓN, J.A., 1991: «Excavación arqueológica en Mirobriga: campañas de 1987-1988», Extremadura Arqueológica II, Mérida-Cáceres.

PASTOR, M. y PACHÓN, J.A., 1993: “Mirobriga. Una ciudad romana en la Siberia extremeña», Revista de Arqueología, 150, Madrid.

PAStoR, M. et ALll, 1992: Mirobriga. Excavaciones en el "Cerro Cabezo" (Capilla, Badajoz). Campañas 1987-1988, Mérida.

PONES, J.M., 1900: Historia de la antigua ciudad de Sisapón, hoy Almadén del Azogue, Madrid.

PfieTo, A.M., 1973: Estructura social del "Conventus Cordubensis» durante el Alto Imperio Romano, Granada.

RoldÁN, J.M., 1975: Itineraria Hispana. Fuentes antiguas para el estudio de las vías romanas en la Península Ibérica, Valladolid-Granada.

Romero, I., 1954: Saesapo, Ciudad Real.

RuIz, J. Fr., 1923: Historia de Hinojosas del Duque, Jerez de la Frontera.

SaAvedra, E., 1862: Discursos leidos ante la Real Academia de la Historia, Madrid.

SANCHO, E. y GARCIA DE LA SANTA, T., 1960: «Un poblado romano en La Bienvenida (Real Valle de Alcudia, Almodóvar del Campo, Ciudad Real)", Cuad. Est. Manch., X, Ciudad Real. 
Saupe, F., 1973: La géologie du gisement de mercure d' Almadén (Province de Ciudad Real, Espagne), Sciences de la Terre. Memoria núm. 27.

SilliéRES, P., 1980: «Sisapo: prospections et decouvertes», Arch. Esp. Arq., LIII, núm. 141-2, pp. 49 y ss.

Sillí́res, P., 1990: Les voies de communiction de l' Hispanie Meridionale, Paris.

STYLow, A.U., 1985: "Ordenación territorial romana en el Valle de los Pedroches (Conventus Cordubensis)", XVII C.N.A., Logroño, 1983, Zaragoza.

VIÑAS, C. y PAZ, R., 1971: Relaciones Histórico-Geográfico-Estadísticas de los pueblos de España hechas por iniciativa de Felipe II (1575 y 1578), Ciudad Real, Madrid.

VIU, J. DE, 1846: Colección de inscripciones y antigüedades de Extremadura, Cáceres.

ZarRaluQui, J., 1934: Los Almadenes de Azogue. La Historia frente a la tradición, Madrid.

ZaRzALEJos, M., 1994 a: Arqueología de la Región Sisaponense. Aproximación a la evolución histórica del área SW. de la provincia de Ciudad Real (fines del siglo VIII a.C.-ll d.C. Tesis Doctoral. Universidad Autónoma de Madrid.

Zarzalejos, M., 1994 b: «La ciudad de Sisapo a la luz de los testimonios documentales antiguos: Fuentes geográficas, literarias, epigráficas y numismáticas" (e.p.).

ZARZALEJOS, M. y GARcía, P., 1987: «Dos gemas talladas romanas de La Bienvenida». Oretum, III, Ciudad Real.

ZARZALEJOS, M. y Seldas, I., 1987: «Anforas romanas en Ciudad Real». Oretum, III, Ciudad Real.

ZARZALEJOS, M. ET ALII, 1993: "Cerámicas griegas de Sisapo (La Bienvenida, Ciudad Real), XXII C.N.A., Vigo (e.p.). 